\title{
Nurses' perceptions of hazards to patient safety in the intensive care units during a nursing staff shortage
}

\author{
Sheuwen Chuang*1,2, Laura M.D. Maguire ${ }^{3}$, Shu-Tai Hsiaoo ${ }^{4}$ Yun-Hsien Ho ${ }^{4,5}$, Su-Fen Tsai ${ }^{6}$ \\ ${ }^{1}$ Graduate Institute of Data Science, Taipei Medical University, Taipei, Taiwan \\ ${ }^{2}$ Health Policy and Care Research Center, Taipei Medical University, Taipei, Taiwan \\ ${ }^{3}$ Department of Integrated Systems Engineering, The Ohio State University, Ohio, USA \\ ${ }^{4}$ Nursing Department, Taipei Medical University Hospital, Taipei, Taiwan \\ ${ }^{5}$ Nursing Department, Country Hospital, Taipei, Taiwan \\ ${ }^{6}$ Department of Medical Research, Taipei Medical University Hospital, Taipei, Taiwan
}

Received: August 22, 2019

DOI: $10.5430 /$ ijh.v6n1p19
Accepted: November 5, $2019 \quad$ Online Published: November 14, 2019

URL: https://doi.org/10.5430/ijh.v6n1p19

\begin{abstract}
Objective: Nursing shortage in acute care had shown a negative impact on patient safety and nurses. This study determines nurses' perceptions of hazards affecting patient safety in the intensive care units (ICUs) of a private regional hospital.

Methods: An initial focus group was used to explore nurses' sense of, and experiences with, hazards affecting patient safety in daily care. This data aided in developing a structured questionnaire to survey ICU nurses. Nonparametric test and $t$ test were applied for inference analysis.

Results: Response rate was $78 \%$ with average age of respondents 28 . Sixty-three hazards were identified and segmented into four domains. Hazards in the Team/Communication domain were the highest risks commonly perceived by all ICU nurses. Less-experienced nurses were more concerned about unfamiliar procedures/equipment and unexpected conditions from both Administration/Maintenance and Patients/Family domains than senior nurses.

Conclusions: The study highlights the complexity of nursing care and hidden nursing management issues, as well as suggests that nurses' perceptions of hazards to patient care could help understand important difference between nursing staff to more specifically address variations to improve the situation.
\end{abstract}

Key Words: Nursing shortage, Patient safety, Perception, Intensive care units

\section{INTRODUCTION}

Intensive care units (ICUs) consistently face nursing shortages and there are high turnover rates in nursing staff worldwide. ${ }^{[1,2]}$ Many studies have identified that the impacts of nurse staffing levels on patient safety and nurses, showing that trends exist between an increase in nurse staffing levels and a decrease in adverse events in intensive care; ${ }^{[3,4]}$ higher patient loads and higher hospital readmission rates; ${ }^{[5]}$ a significant positive association between nurse burnout and poor quality care, especially in infection rate and mortality rate. ${ }^{[6]}$ Consequently, the difficult working conditions faced by professional nurses are exacerbating the nursing shortage. ${ }^{[7]}$ There is evidence to support it is imperative to help nursing staff to maintain quality care to counter the effects of the nursing shortage, working pressure, unsatisfactory patient safety, and difficulty of retaining registered nurses. ${ }^{[8]}$

*Correspondence: Sheuwen Chuang; Email: sheuwen@tmu.edu.tw; Address: Health Policy and Care Research Center, No. 172-1 Sec. 2 Keelung Rd., Taipei, Taiwan. 
In Taiwan, problems associated with long-term nursing shortages have serious consequences. The turnover rate of qualified nurses is high, which shows only $60 \%$ of licensed nurses stay in clinical nursing jobs. ${ }^{[9]}$ Recent surveys reported that more than $75 \%$ of hospitals in Taiwan have difficulty recruiting and retaining a sufficient number of nurses. ${ }^{[10,11]}$ In the face of the challenges of nursing shortage in Taiwan, hospitals' administration had aggressively sought effective strategies for recruitment and retention of registered nurses (RNs) including incentives such as salary increases or bonuses and improved working environments. ${ }^{[12]}$ Additionally, in order to increase nurse staffing in ICUs, some hospitals modified their previous qualifications (a requirement to have worked in a general ward for more than one year before being an ICU nurse), and allowed enthusiastic recently-graduated nurses with an RN license to immediately work in the ICU after receiving two months of ICU basic care training. This situation has thus created a working environment in which nurses have highly variable levels of work experience in ICUs challenging hospitals' ability to provide safe, quality care to patients and impacting satisfaction of nurses in acute and critical care units. ${ }^{[13]}$ Hospitals therefore suffered a negative feedback in the causal loop related to the nursing shortage which increased nurses' working pressure and burden, unsatisfactory patient safety outcomes and developing recruiting challenges in retaining registered nurses. It has raised a serious concerned in Taiwan's medical care systems. ${ }^{[8]}$

The purpose of this study is threefold: 1) to examine the ICUs' nurses perceptions in a private regional hospital in Taiwan that has suffered long-term nursing shortage and unsatisfactory patient safety goals, and determine what their perceived hazards (hazardous situations) to patient safety were, 2) to identify the differences based on ICU working seniority, and 3) to draw conclusions about the implications of these findings on hospital's potential resolutions to nursing shortage and patient safety issues in order to improve the negative feedback loop.

\section{MeTHODS}

\subsection{Setting}

The setting is a private regional hospital with two ICUs: an 18-bed surgical ICU (SICU) and a 24-bed medical ICU (MICU), with an average monthly occupation rate above $95 \%$. The annual turnover rates of nurses were $30 \%-39 \%$ in recent years. The ICUs' performance for patient safety outcomes had been concerning. Taking the hospital acquired infection (HAI) as an example of referred index, respective overall infection densities between 2011 and 2013 were $20.2 \%$, $9.4 \%$, and $10.1 \%$ in the SICU and $15.9 \%$, $10.2 \%$, and $9.9 \% \circ$ in the MICU. As a comparison, the average ICU infection densities of regional hospitals in Taiwan: $8.0 \%$, $8.0 \%$, and $6.8 \%$ in SICUs and $6.7 \%$, $5.9 \%$, and $4.8 \%$ in MICUs. ${ }^{[14]}$ Conclusively, the setting had poorer performance in HAI than the average performance of regional hospitals nationwide.

\subsection{Design}

The research method is grounded in systems theory and the concept of cognitive map. According to systems theory and the perception concept, individuals have cognitive maps which order their perceptions and conceptions in order to make sense of the world around them and of their place in it. The "map" depicts a mental representation (model) of one's environment and one's relationship to it in as much as it is the image, as though it is an exact representation of external reality. ${ }^{[15,16]}$ In addition, the definition of hazards defined by the International Standard Organization (ISO) were adopted to explore nurses' perception of hazards to patient safety. The definition of hazard is "A hazard is a source of any actual or possible threat of potential damage, harm, or adverse health effects on something or someone under certain conditions at work."[17]

\section{Mixed methods}

A mixed methods design, including the use of focus group techniques and surveys, was adopted in two stages. The first stage was to collect nurses' perceived hazards to patient safety in ICUs. A focus group was held composed of eight participants, including two head nurses of the two ICUs, and six nurses representing 3-60 months of work experience from both ICUs. The purpose in using the focus group was to explore nurses' sense of and experiences with hazards affecting patient safety in daily care. Since HAI had been a major issue in the two ICUs and was known by all participants, the associated factors with HAI was initially used as an example to start the discussion, and triggered the subsequent discussion of overall relevant hazards to safe care in ICUs. Three rounds of focus group meetings were undertaken to generate a clear list of hazards.

Hazards that potentially affected patient safety in the ICUs were discussed and transcribed verbatim for each participant in the first round. To obtain consistent agreement of the hazards among the participants and ensure the validity, the description of individual hazards were clarified and refined with the deletion of duplication in the following two rounds. Finally, a researcher extracted keywords from the hazards with long-form descriptions, followed by synthesis into a short excerpt (i.e., being overloaded), or a generalized description (i.e., nurse had insufficient knowledge and skills in care) from the detailed sentences relevant to the skills and knowledge of nursing care, such as "pressurization duration when

ISSN 2377-7338 E-ISSN 2377-7346 
arterial line was removed," "pain control (drugs and those biological presenting)." Next, additional two researchers verified the extracted keywords and determined the hazards (63 hazards) and grouped them into ten categories (A-J) under four domains (Team/Communication, Training/Manpower, Patient/Family, and Administration/Maintenance) based on their relevance (see Table 1).

Table 1. 63 hazards in ten categories within four domains

\begin{tabular}{|c|c|c|c|c|c|}
\hline \multirow{15}{*}{ 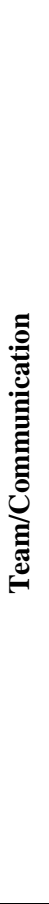 } & A1 & Doctor's oral medical orders (MOs) were not clear & \multirow{12}{*}{ 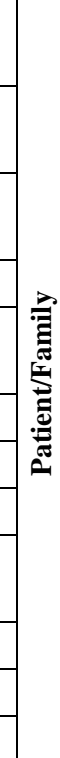 } & G1 & $\begin{array}{l}\text { Nurse did not communicate with patient's } \\
\text { family }\end{array}$ \\
\hline & A2 & Oral MOs provided at the time not on duty & & G2 & $\begin{array}{l}\text { Poor communication between nurse and } \\
\text { patient's family }\end{array}$ \\
\hline & A3 & Repeating doctor's oral MOs was unclear & & G3 & $\begin{array}{l}\text { Argument between healthcare worker and } \\
\text { patient's family }\end{array}$ \\
\hline & A4 & Poor communication between doctor and nurse & & G4 & Bad attitudes of nurses \\
\hline & A5 & Poor telephone communication between doctor and nurse & & G5 & $\begin{array}{l}\text { Insufficient explanations for treatment and } \\
\text { care }\end{array}$ \\
\hline & B1 & Unclear handover between nurse's shifts in different units & & H1 & Extubation failed due to an agitated patient \\
\hline & B2 & Poor communication between nurse's shifts inside one unit & & $\mathrm{H} 2$ & Patient confusion \\
\hline & B3 & Incorrect handover & & H3 & Patient is delirious \\
\hline & B4 & Handover in sudden or emergent conditions & & $\mathrm{H} 4$ & $\begin{array}{l}\text { Patient's family requested staff to let patient } \\
\text { go home }\end{array}$ \\
\hline & B5 & Handover between novices & & H5 & Changes in patient's disease status \\
\hline & B6 & Incomplete or imprecise handover records in a busy situation & & H6 & Complexity of patient's disease is too high \\
\hline & C1 & Lack of respect between nurses & & H7 & Uncertainty in ICU \\
\hline & $\mathrm{C} 2$ & Lack of cooperation, understanding, trust, and respect in a team & \multirow{25}{*}{ 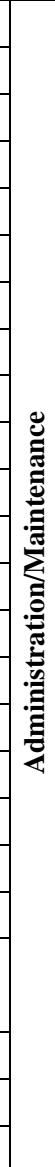 } & $\mathrm{I} 1$ & Poor quality of equipment and devices \\
\hline & C3 & Lack of respect between doctors and nurses & & $\mathrm{I} 2$ & Malfunction of equipment and devices \\
\hline & $\mathrm{C} 4$ & Poor communication between cross-team & & I3 & Power failure \\
\hline \multirow{22}{*}{ 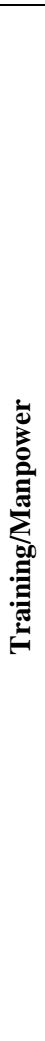 } & D1 & Insufficient nurse manpower in the ICU & & $\mathrm{I} 4$ & Loss of air pressure from the central air supply \\
\hline & D2 & Being overloaded & & I5 & Electrical spark \\
\hline & D3 & Working with part-time worker & & I6 & Insufficient supply of sanitary material \\
\hline & D4 & Nurse-to-patient ratio on the morning shift is inadequate $1: 3$ & & \multirow{2}{*}{ I7 } & \multirow{2}{*}{ Poor quality of sanitary material } \\
\hline & D5 & Nurse-to-patient ratio on the night shift is inadequate 1:4 & & & \\
\hline & E1 & Training is insufficient & & \multirow{2}{*}{ I8 } & \multirow{2}{*}{$\begin{array}{l}\text { Insufficient supply of drugs and carts for } \\
\text { emergency cases }\end{array}$} \\
\hline & E2 & Reduced training time for novices & & & \\
\hline & E3 & Many novices & & \multirow{2}{*}{ I9 } & \multirow{2}{*}{$\begin{array}{l}\text { Poor stock management of pharmacy and } \\
\text { sanitary material }\end{array}$} \\
\hline & E4 & Nurse was lack of knowledge & & & \\
\hline & E5 & Nurse had inadequate attitude and poor execution & & \multirow{2}{*}{$\mathrm{J} 1$} & \multirow{2}{*}{ Inadequate quality control } \\
\hline & F1 & Non-compliance with infection-prevention procedures & & & \\
\hline & F2 & Non-compliance with SOPs due to complex ICU surroundings & & \multirow{2}{*}{$\mathrm{J} 2$} & \multirow{2}{*}{$\begin{array}{l}\text { Poor environmental design for movement - } \\
\text { Infection control issues }\end{array}$} \\
\hline & F3 & Non-compliance with medication rules & & & \\
\hline & F4 & Inadequate patient identification & & \multirow{3}{*}{ J3 } & \multirow{3}{*}{$\begin{array}{l}\text { Inadequate training management of cleaning } \\
\text { workers }\end{array}$} \\
\hline & F5 & Use of incorrect aseptic method & & & \\
\hline & F6 & Incorrectly operating instrument & & & \\
\hline & F7 & Incorrectly washing hands & & \multirow{2}{*}{$\mathrm{J} 4$} & \multirow{2}{*}{ Unclear policy or standards } \\
\hline & F8 & For convenience purpose, directly reinsert the slipped urine bag & & & \\
\hline & & into the patient & & \multirow{2}{*}{ J5 } & \multirow{2}{*}{ Inadequate advocacy to the revised SOP } \\
\hline & F9 & Inadequate sterile concept/lack of awareness & & & \\
\hline & F10 & CVC/VAP/UTI Bundle care incorrect & & \multirow{2}{*}{ J6 } & \multirow{2}{*}{$\begin{array}{l}\text { Clinical care information and nursing } \\
\text { information systems were unstable or crashed }\end{array}$} \\
\hline & F11 & ICU infection control/ protection incorrect & & & \\
\hline
\end{tabular}


In the second stage, a structured questionnaire was designed on the basis of Table 1 . The questionnaire was evaluated by one health care faculty and two nurse managers (Kappa = 0.92 , almost perfect agreement). The structured questionnaire collected respondents' demographic and professional data in the first part, followed by 63 questions corresponding to the finalized 63 hazards identified in the first stage. The questionnaire asked nurses whether they agree or disagree that each hazard might cause unsafe care. A 5-point Likert scale was used to indicate the perceived risk level of a hazard that could affect patient safety. A higher mark on this scale indicated a higher perceived risk. The questionnaire was validated by an expert panel composed of two doctoral degree faculty and two senior nurses. The study was approved by the investigators' university Institutional Review Board. A survey of the questionnaire was distributed to all 60 nurses working in the two ICUs and conducted in the period from November to December 2013. Responses were received anonymously.

Data analysis used SPSS v19. A descriptive analysis of respondent's characteristics and answers, including nurses' agreement on perception of hazards and perceived risk level of each hazard, was conducted. A $t$ test was used to deter- mine if the averages of agreement ratio and perceived risk level by categories are significantly different between the two ICUs' nurses. However, considering the sample may not be normal distribution due to its small size, the study also adopted Wilcoxon Rank-Sum Test to test the hypothesis of equal medians for the two independent unequal-sized ICU nurse groups, and one-way non-parametric ANOVA (Kruskal-Wallis test) with Dunn-Bonferroni post hoc method to analyze the differences among seniority groups for their association analysis.

\section{RESULTS}

\subsection{Nurses' characteristics}

Forty-five of the questionnaires were returned, giving response rates of $74 \%(26 / 35)$ in the MICU and $76 \%$ (19/25) in the SICU. Table 2 indicates that the SICU had more novices and younger nurses than the MICU. The average age of all respondents was 28 years, $58 \%$ of respondents in the SICU and $19 \%$ in the MICU were younger than 26 years. Furthermore, $68 \%$ of nurses had worked in the SICU and $27 \%$ had worked in the MICU for less than 2 years, and most nurses began their ICU work at this hospital. The $t$-test found a significant difference of ICU working seniority between the two ICUs' nurses $(p<.001)$.

Table 2. Demographic and professional characteristics of nurses

\begin{tabular}{|c|c|c|c|c|}
\hline \multirow[b]{2}{*}{ Age (years) mean and SD } & \multicolumn{2}{|c|}{ MICU (n = 26) } & \multicolumn{2}{|c|}{$\operatorname{SICU}(n=19)$} \\
\hline & 31.0 & 4.4 & 27.5 & 4.1 \\
\hline \multirow[t]{2}{*}{ median and IQR } & 30.0 & $27.75-31.25$ & 26.0 & $25.00-29.00$ \\
\hline & $n$ & $\%$ & $n$ & $\%$ \\
\hline$<26$ & 5 & 19 & 11 & 58 \\
\hline $26 \sim 30$ & 14 & 54 & 3 & 16 \\
\hline$\geq 31$ & 7 & 27 & 5 & 26 \\
\hline Length of experience in ICUs (months) mean and SD & 52.5 & 43.1 & 28.8 & 28.8 \\
\hline median and IQR & 43.5 & $19.00-78.00$ & 15 & $6.00-54.00$ \\
\hline seniority $\leq 6$ & 1 & 3.8 & 6 & 31.6 \\
\hline $6<$ seniority $\leq 12$ & 4 & 15.4 & 3 & 15.8 \\
\hline $12<$ seniority $\leq 24$ & 2 & 7.7 & 4 & 21.1 \\
\hline $24<$ seniority $\leq 60$ & 12 & 46.2 & 5 & 26.3 \\
\hline seniority $>60$ & 7 & 26.9 & 1 & 5.2 \\
\hline \multicolumn{5}{|l|}{ Certificate } \\
\hline Registered nurse & 24 & 92.3 & 19 & 100 \\
\hline Licensed practical nurse & 2 & 7.7 & 0 & 0 \\
\hline N1 & 8 & 30.8 & 4 & 21.1 \\
\hline N2 & 10 & 38.4 & 4 & 21.1 \\
\hline None & 8 & 30.8 & 11 & 57.8 \\
\hline
\end{tabular}

Note. SD: standard deviation; IQR: interquartile range 


\subsection{Perceived hazards to patient safety}

The collection of nurses' perceived hazards to patient safety (see Table 1) provides a variety of specific local situations in how nurses sensed these potential dangers in ICUs. For example, five hazards in the category A demonstrate that nurses' perceptions about hazards were related to the poor communication between nurses and doctors, some of which were expressed in the general description, others were described as the occurrences of the relevant hazards in a specific way, time and channel. Additionally, the nurses' perceptions of hazards horizontally and broadly covered every dimension surrounding nursing care, which were synthesized into four domains. For example, the domain Administration/Maintenance includes hazards related to policy, quality management, material/hardware/software, and information.

Table 3. Hazards with perceived risk level to patient safety were above the 80th percentile

\begin{tabular}{lllll}
\hline Rank & MICU & Risk level & SICU & Risk level \\
\hline 1 & B5 & 4.44 & B5 & 4.11 \\
2 & A1 & 4.08 & A1 & 3.84 \\
3 & D1 & 4.04 & A2 & 3.58 \\
4 & E4 ${ }^{*}$ & 4.04 & B4 & 3.58 \\
5 & A2 & 4 & E3 & 3.58 \\
6 & E3 & 4 & B6 & 3.44 \\
7 & B6 & 3.96 & H7 & 3.44 \\
8 & E5 & 3.92 & A3 ${ }^{*}$ & 3.42 \\
9 & D2 & 3.79 & E2 & 3.42 \\
10 & F3 & 3.63 & F3 & 3.37 \\
11 & F1 & 3.46 & E5 & 3.33 \\
12 & B4 & 3.42 & D2 & 3.32 \\
13 & D5 & 3.38 & D1 & 3.26 \\
14 & F2 & 3.38 & & \\
15 & H7 & 3.38 & & \\
\hline Note. ${ }^{*}$ only appeared in one ICU; MICU: medical intensive care unit; & SICU: surgical intensive care unit. & &
\end{tabular}

Based on the analysis of the perceived hazards with higher risk levels on the basis of the 80th percentile, the study found that there were 15 hazards on the MICU list and 13 on the SICU list (see Table 3). Handover between novices (B5) was perceived as the top hazard by the ICUs nurses. Hazards in the two lists were perceived similarly by the ICUs nurses, except for D5 (nurse-to-patient ratio on the night shift is inadequate), E4 (lots of novices working at the same period of time), F1 (non-compliance with procedures for infection prevention), and F2 (not following standard operating procedures [SOPs] due to the complex ICU surroundings) which only appeared in the MICU list; and A3 (lack of respect between nurses) and E2 (training time is insufficient) which only appeared in the SICU list. Overall, the domains of Train-
ing/Manpower and Team/Communication were perceived by all nurses as having higher risk to patient safety than Patients/Family and Administration/Maintenance hazards.

\subsection{Nurses' perception on the agreement of hazards to patient safety}

Table 4 describes the agreement ratio (agreeing respondents divided by total respondents) and the average nurses' perceived risk level (total perceived risk levels divided by total respondents) on individual hazards in ten categories, and their corresponding average by domains. Regarding the comparison between the two ICUs, the study reveals that the SICU nurses had significantly greater concerns (higher average agreement ratios) about the hazards than the MICU nurses in all four domains ( $p=.0092$ ), especially in the Team/Communication domain which SICU's agreement ratio is significantly higher than the MICU $(p=.0375)$. Thirtytwo of the 63 hazards showed complete agreement (100\%) by SICU nurses, while only five hazards were in complete agreement by the MICU nurses. Overall, a significant difference of nurses' perceived agreement on individual hazards was found between the two ICUs (Wilcoxon RankSum Test, $p<.001)$. Within each ICU, hazards in the domains Team/Communication and Training/Manpower were agreed to have more of an effect on patient safety than the other two domains' hazards. The issues of Administration/Maintenance were the lowest. The Kruskal-Wallis test shows that category $\mathrm{J}$ were found to be in significantly less agreement than categories A, B, D, E, F, and $\mathrm{H}$ within the MICU nurses $(p<.028, p<.007, p<.001, p<.001, p<$ .002 and $p<.043$, respectively). No significant difference in perceived agreement on hazards among categories was found within the SICU nurses' perceptions.

\subsection{Perceived risk levels of hazards to patient safety}

Regarding the comparison of nurses' perceived risk level of hazards by category level (see Table 4), both ICU's nurses showed moderate concerns (3.49 in MICU, 3.22 in SICU), but no significant differences were found $(p=.092)$. Further, for the nurses' perceived risk level on individual hazards in the same category between the two ICUs, the study found no significant differences (Wilcoxon Rank-Sum Test, $p=.065$ ). This indicated that nurses agreed on individual hazards affecting safe care in a category, and their perceived levels of the hazard's risk on safe care within the same category were similar between the two ICUs. The comparison of the perceived risk levels of individual hazards between different categories within each ICU, however, was found to be significantly different (Kruskal-Wallis test, $p \leq .001$ ). DunnBonferroni's test identified that 12 pairs (categories J-A, J-B, J-E, J-F, J-H; categories I-A, I-B, I-E, I-F; and categories 
G-B, G-D, G-E) in the MICU and 7 pairs (categories J-A, $\mathrm{J}-\mathrm{B}, \mathrm{J}-\mathrm{E}, \mathrm{J}-\mathrm{H}$; and categories I-A, I-B, I-E) in the SICU, the nurses' perceived risk levels of hazards significantly differed. This finding revealed that category $\mathbf{J}$ (issues of management or administration, i.e., unclear policy or standards, see Table 1) and category I (issues of medical hardware and supplies, i.e., malfunction of equipment and devices) relatively were perceived as a smaller risk than other categories within each ICU.

\subsection{Associations between nurses' seniority and their per- ceived risk levels of hazards}

With regards to seniority in the ICUs, the study found significant negative associations $(p<.05)$ between nurses' seniority and their perceived levels of risk through Kruskal-Wallis one-way ANOVA with post-hoc analysis (see Table 5). This indicated that nurses with less working experience in the two
ICUs were more concerned about the hazards in the domain of Administration/Maintenance, followed by Patient/Family and Training/Manpower. Significant differences in nurses' perception of hazardous conditions in the two ICUs were found between nurses with $<36$ months of working experience in ICUs (groups 1 and 2) and those with greater seniority (groups 3 and 4). Hazards in category I (i.e., Malfunction of equipment and devices [I2], Power failure [I3], loss of air pressure from the central air supply [I4], Electrical spark [I5], Poor quality of sanitary material [I7], Insufficient supply of drugs and carts for emergency cases [I8], Poor stock management of pharmacy and sanitary material [19], inadequate advocacy to the revised SOP [J5]), were of greater concern to novice nurses (group 1) than the nurses in groups 3 and 4. However, the perceived risk level of Team/Communication hazards were found no significant difference between nurses' seniority groups.

Table 4. Nurses' perceptions of hazards affecting patient safety

\begin{tabular}{|c|c|c|c|c|c|c|c|}
\hline \multirow{2}{*}{ 芯 } & \multirow{2}{*}{\multicolumn{2}{|c|}{ Category }} & \multirow[b]{2}{*}{$\mathbf{N}$} & \multicolumn{2}{|c|}{ MICU (n = 26) } & \multicolumn{2}{|c|}{ SICU (n = 19) } \\
\hline & & & & $\begin{array}{l}\text { Agreement } \\
\text { ratio (\%) }\end{array}$ & $\begin{array}{l}\text { Average perceived } \\
\text { risk level }\end{array}$ & $\begin{array}{l}\text { Agreement ratio } \\
(\%)\end{array}$ & $\begin{array}{l}\text { Average perceived } \\
\text { risk level }\end{array}$ \\
\hline \multirow{4}{*}{ 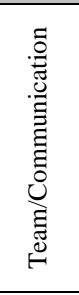 } & A & $\begin{array}{l}\text { Poor communication between } \\
\text { nurses and doctors }\end{array}$ & 5 & 87.9 & 3.85 & 98.9 & 3.48 \\
\hline & B & Handover issues between nurses & 6 & 89.3 & 3.89 & 98.2 & 3.46 \\
\hline & $\mathrm{C}$ & Poor teamwork & 4 & 82.9 & 3.21 & 100 & 3.20 \\
\hline & $\begin{array}{l}\text { Dor } \\
t \text { tes } \\
t \text { tes }\end{array}$ & $\begin{array}{l}\text { ain average } \\
\text { of agreement ratio on domain: } \boldsymbol{p}=\text {. } \\
\text { of average risk level on domain: } p=\end{array}$ & $\begin{array}{l}75^{*} \\
32 \\
\end{array}$ & 86.7 & 3.65 & 99.0 & 3.38 \\
\hline \multirow{5}{*}{ 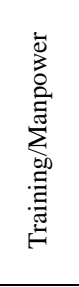 } & $\mathrm{D}$ & Nursing manpower insufficient & 5 & 94.4 & 3.85 & 90.5 & 3.60 \\
\hline & $\mathrm{E}$ & Inadequate training & 5 & 97.7 & 3.87 & 100 & 3.43 \\
\hline & $\mathrm{F}$ & $\begin{array}{l}\text { Failure to comply with standard } \\
\text { procedures }\end{array}$ & 11 & 88.4 & 3.45 & 96.1 & 2.99 \\
\hline & Dor & ain average & & 93.5 & 3.72 & 95.5 & 3.34 \\
\hline & & $\begin{array}{l}\text { of agreement ratio on domain: } p=\text {. } \\
\text { of average risk level on domain: } p=\end{array}$ & & & & & \\
\hline \multirow{3}{*}{ 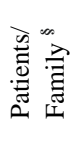 } & G & Poor nurse-patient relationships & 5 & 75.1 & 3.05 & 94.4 & 2.92 \\
\hline & $\mathrm{H}$ & Patient or patient's disease issues & 7 & 85.5 & 3.44 & 91.3 & 3.42 \\
\hline & Do & ain average & & 80.3 & 3.24 & 92.8 & 3.17 \\
\hline \multirow{3}{*}{ 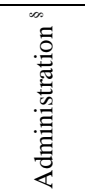 } & I & $\begin{array}{l}\text { Issues of medical hardware and } \\
\text { supplies }\end{array}$ & 9 & 74.6 & 3.01 & 90.1 & 3.07 \\
\hline & $\mathrm{J}$ & $\begin{array}{l}\text { Issues of management or } \\
\text { administration }\end{array}$ & 6 & $67.6^{\ddagger}$ & 3.23 & 88.9 & 2.62 \\
\hline & Do & ain average & & 71.1 & 3.12 & 89.5 & 2.84 \\
\hline \multicolumn{8}{|c|}{$\begin{array}{l}\text { Test of difference between groups -Agreement ratio test: } \\
\qquad\left(p=.0098^{*}\right)\end{array}$} \\
\hline & & Total mean/SD/Median & & 84.3/9.41/86.7 & & $94.3 / 4.22 / 94.4$ & \\
\hline \multicolumn{8}{|c|}{$\begin{array}{l}\text { Test of difference between groups -Perceived risk level: } \\
\qquad(p=.092)\end{array}$} \\
\hline & & Total mean/SD/Median & & & $3.49 / 0.356 / 3.45$ & & $3.22 / 0.313 / 3.31)$ \\
\hline \multicolumn{4}{|c|}{$\begin{array}{l}\text { Significant difference is found among categories within an } \\
\text { ICU }\left(\boldsymbol{p}<\mathbf{. 0 0 1}^{*}\right)\end{array}$} & $\mathrm{J}^{\ddagger}$ & - & - & - \\
\hline
\end{tabular}

Note. $\mathrm{N}$ : number of questions in the category, MICU: medical intensive care unit; SICU: surgical intensive care unit. ${ }^{*} p<.05,{ }^{\S}$ : Failure to perform $t$ test due to too few data, ${ }^{\ddagger}$ the category is significant different from other categories within an ICU. 
Table 5. Significant differences between seniority groups in comparisons of perceived risk level of hazards $(p<.05)$

\begin{tabular}{|c|c|c|c|c|c|}
\hline \multirow{2}{*}{ Seniority group (I) } & \multirow{2}{*}{ Seniority group (J) } & \multicolumn{3}{|c|}{ Median difference $(\mathrm{I}-\mathrm{J})>0$} & \multirow{2}{*}{ Total hazards } \\
\hline & & Domain & Hazard & Count & \\
\hline \multirow{4}{*}{ Group $1(\mathrm{n}=8)$} & \multirow{3}{*}{ Group $3(n=11)$} & Training & E2 & 1 & \multirow{3}{*}{12} \\
\hline & & Patients & G2; G5; H1 & 3 & \\
\hline & & Administration & I2; I3; I4; I5; I7; I8; I9; J5 & 8 & \\
\hline & Group $4(\mathrm{n}=12)$ & Administration & J5 & 1 & 1 \\
\hline \multirow{4}{*}{ Group $2(n=14)$} & \multirow{3}{*}{ Group $3(n=11)$} & Training & E2; E3; F6 & 3 & \multirow{3}{*}{11} \\
\hline & & Patients & G3; H1 & 2 & \\
\hline & & Administration & I5; I7; I8; I9; J2; J3 & 6 & \\
\hline & Group $4(n=12)$ & Administration & J6 & 1 & 1 \\
\hline
\end{tabular}

Note. Group 1: Seniority < 7 months; Group 2: 7 months $\leq$ seniority $<36$ months; Group 3: 36 months $\leq$ seniority $\leq 54$ months; Group 4: Seniority $>54$ months

\section{DiscuSSION}

The study reveals rich information about the cognitive lenses of nurses' in their respective ICU surroundings, which highlights the following important themes that are necessary to be considered in improving the negative feedback loop of nursing shortage and unsatisfied outcomes.

\subsection{The essential nature of the nurses' cognitive maps}

Healthcare systems are complex and are inherently, and often unavoidably, hazardous by their very nature. ${ }^{[18]}$ Healthcare workers at the point of care delivery are involved in constantly evolving situations that are both supported and constrained by organizational resources. Accordingly, they continuously perform activities influenced by their own cognitive factors - including knowledge, mindset, and goals to manage clinical practice situations. ${ }^{[19]}$ The 63 perceived hazards identified by the focus group show varied forms of describing similar hazards. Some nurses emphasized specific location, size, methods, timing and particular circumstances about the hazards, while others used general descriptions for the hazards, i.e., poor communication between nurses and doctors. Furthermore, the nurses' cognitive maps of harm to patient safety also extensively included unpredictability, uncertainty, poorly designed layout, resource constraints, incapable workers, unsatisfied teamwork, time pressures, missing data, malfunctions of equipment and information systems that potentially affect patient safety.

Based on mental model theory, ${ }^{[16]}$ these perceptions of hazards reflect two essential natures of nurses' cognitive maps: nursing care in ICUs involves a complex series of physical and cognitive activities; ${ }^{[19]}$ nurses' work patterns involve management of complicated cognitive work and environmental issues in the midst of delivering individualized care under pressure. ${ }^{[20]}$ The two essential natures exacerbate the reality that the nursing work environment - including professionalism, co-worker relationship, management, staffing and resources, and ward practice - has a significant bearing on nurses' job satisfaction and intention to leave, ${ }^{[20]}$ consequently impacting patient safety. ${ }^{[6]}$ This study evidenced the high turnover rates of nurses in the two ICUs and unsatisfied patient outcomes. Researches advocate that failure to understand the work of care providers in actual caregiving situations is a major stumbling point in making real progress. ${ }^{[19,21]}$

\subsection{The hidden areas of management issues}

Two instances of nurses' cognitive maps were revealed. One is the common highly risky hazards perceived and agreed on by ICU nurses. The other is the perception gaps of hazards. The findings highlight the hidden areas of management issues that the hospital should pay attention to.

The common cognitive maps on hazards to patient safety include the hazards in the domain's Team/Communication and Training/Manpower. These hazards were highly agreed upon and perceived as the top two strongest risk levels by all ICU nurses without significant differences between seniority groups. This may imply a common lack of confidence in teamwork and poor communication in ICU care systems in this hospital. This common risk situation in health care led to conceivable consequences to the clinicians working in critical care, such as moral distress and burnout, ${ }^{[22]}$ individual care provision was influenced by the interdisciplinary tensions, ${ }^{[23,24]}$ and less collaboration between nurses and physician, as well as among nurses. ${ }^{[25]}$ Moreover, lack of respectful communication, workplace bullying, and emotional exhaustion all had significant direct effects on job satisfaction, which in turn, was related to higher turnover intentions. ${ }^{[26,27]}$ These areas should be given higher priority for improvement.

The study reveals that the two ICUs had highly variable levels of work experience of nursing staff. Perception gaps were found between the two ICUs, as well as different working 
seniority groups of all nurses, which include the hazards in the Administration/Maintenance and Patients/Family domain. These hazards were perceived as being more risky to patient safety by junior nurses than by senior nurses. The findings may imply that younger and less-experienced nurses were more concerned about unfamiliar procedures or equipment and unexpected conditions from both Administration/Maintenance and Patients/Family domains than were senior nurses. This is inherently reasonable, as less experienced nurses have faced less variability in their work and may not be able to apply their skills as effectively in novel or unexpected conditions. ${ }^{[28]}$ Specifically designed training programs or opportunities for greater mentorship are needed to deal with the perception gaps.

\subsection{Opportunities to improve the predicament situation}

Based on the findings, the study team suggests the following recommendations for improving the predicament of nursing shortage and unsatisfied patient outcomes.

\subsubsection{Refinement of training programs}

The hospital adopted a quick training approach combined with later continuous training to expedite and enhance the learning of novice nurses. According to the study's findings, refining the novice nurses' training program should be considered to provide more content related to Administration/Maintenance that can challenge their application of procedures and protocols in different scenarios. ${ }^{[29]}$ In addition, specially designed simulation training related to the domain Patient/Family and Training/Manpower for all nurses to develop better strategies for ICU care team collaboration to address the uncertainty they face in their work, as well as knowledge sharing between different seniorities across seniority levels. ${ }^{[19,30]}$ Furthermore, the adoption of transformational leadership training also could improve nurses' situational awareness and mindset, and create positive outcomes to combat the nursing shortage. ${ }^{[22]}$

\subsubsection{Advancement of teamwork and communication}

Relying on an assumption that nursing competency is a major problem of our healthcare today fails to recognize what hospitals essentially need to improve for quality care - especially under the context of nursing shortage. ${ }^{[31]}$ The study reveals that teamwork and communication were the com- monly ranked high-risk hazards and their effects on nurses manifest in a working environment that can be experienced as hostile, abusive or unrewarding, ${ }^{[32]}$ and lead to less collaborative teams. ${ }^{[26]}$ This shows these hazards are not skill, technology, or procedure-related risks to patient safety but rather related to the psychosocial support for nurses.

The study team suggests that the use of interdisciplinary forums that address the psychosocial aspects of care can improve the sense of support and decrease work-related stress and isolation that participants may otherwise feel. ${ }^{[25]}$ Additionally, appropriate support and encouragement in everyday work might be positively associated with work engagement among hospital nurses, which is mediated through the positive psychosocial work environment of the unit. ${ }^{[33]}$ Overall, reinforcement of leadership styles focused on people and relationships (transformational, resonant, supportive, and considerate) could be able to bridge communication between team members and create higher nurse job satisfaction. ${ }^{[34]}$

\section{Conclusions}

The growing nursing shortage will continue to impact patient safety. The delivery of nursing care in an acute care setting involves a complex series of physical, as well as cognitive activities. The study emphasizes that nurses' perceptions of hazards to patient care could help understand the important differences between nursing staff to more specifically address variations to improve the situation. The paper presents a more integrated analysis of the ICU nursing working environments that create risk for patients in care and impact on nurses. It highlights hidden but common high-risk areas and the perception gaps between different seniority groups, as well as identifies opportunities for hospitals similar situations in nurse shortages and poor quality of care outcomes. Based on the findings, to mitigate nursing shortages in the future, the study team suggests to refine relevant training programs and continuously advance teamwork and communication through interdisciplinary forums and appropriate support and encouragement in everyday work for improving the predicament of nursing shortage and unsatisfied patient outcomes.

\section{CONFLICTS OF INTEREST DISCLOSURE}

The authors declare no conflicts of interest.

\section{REFERENCES}

[1] Aluttis C, Bishaw T, Frank MW. The workforce for health in a globalized context-global shortages and international migration. Glob Health Action. 2014; 7(1): 23611. PMid:24560265. https: //doi.org/10.3402/gha.v7.23611
[2] Chan ZC, Tam WS, Lung MK, et al. A systematic literature review of nurse shortage and the intention to leave. J Nurs Manag. 2013; 21(4): 605-613. PMid:23406374. https://doi.org/10.1111/j . $1365-2834.2012 .01437 . x$ 
[3] Kalisch BJ, Xie B, Dabney BW. Patient-reported missed nursing care correlated with adverse events. Am J Med Qual. 2014; 29(5): 415-422. PMid:24006031. https ://doi.org/10.1177/106286 0613501715

[4] McGahan M, Kucharski G, Coyer F. Nurse staffing levels and the incidence of mortality and morbidity in the adult intensive care unit: a literature review. Aust Crit Care. 2012; 25(2): 64-77. PMid:22515951. https://doi.org/10.1016/j.aucc.2012.03.003

[5] Tubbs-Cooley HL, Cimiotti JP, Silber JH, et al. An observational study of nurse staffing ratios and hospital readmission among children admitted for common conditions. BMJ Qual Saf. 2013; 22(9): 735-742. PMid:23657609. https://doi .org/10.1136/bmjqs-2 012-001610

[6] Cimiotti JP, Aiken LH, Sloane DM, et al. Nurse staffing, burnout, and health care-associated infection. Am J Infect Control. 2012; 40(6): 486-490. PMid:22854376. https ://doi.org/10.1016/j.ajic .2012 .02 .029

[7] Nardi DA, Gyurko CC. The global nursing faculty shortage: Status and solutions for change. J Nurs Scholarsh. 2013; 45(3): 317-326. PMid:23895289. https : //doi.org/10.1111/jnu. 12030

[8] Chang LY, Yu HH, Chao YFC. The Relationship Between Nursing Workload, Quality of Care, and Nursing Payment in Intensive Care Units. J Nurs Res. 2018. PMid:29613879. https ://doi .org/10 $.1097 / \mathrm{jnr} .0000000000000265$

[9] Chang M, Yu YM, Chen YC, et al. A study of nursing manpower planning in Taiwan. Formos J Med. 2005; 9(2): 149-156. Chinese.

[10] Lin CF, Huang CI, Kao CC, et al. The nursing shortage and nursing retention strategies in Taiwan. J Nurs. 2013; 60(3): 88-93. Chinese.

[11] Teng SW. Nursing manpower and solutions in Taiwan. Hu Li Za Zhi. 2014; 61(2): 5. Chinese.

[12] Yu HY, Tang FI, Chen IJ, et al. Inactive nurses in Taiwan: human capital, intention to return to hospital nursing, and incentives for returning. J Nurs Manag. 2016; 24(3): 347-356. PMid:26251045. https://doi.org/10.1111/jonm.12328

[13] Dai HD, Tang FI, Chen IJ, et al. Taiwanese version of the WorkRelated Quality of Life Scale for nurses: Translation and validation. J Nurs Res. 2016; 24(1): 58-67. PMid:26859737. https: //doi.org/10.1097/jnr.0000000000000142

[14] Centers for Disease Control of Republic of China (Taiwan). (2011, 2012, 2013). Annual Report of Nosocomial Infection Surveillance System. Available from: http://www.cdc.gov.tw/english/i nfo. aspx?treeid=00ED75D6C887BB27\&nowtreeid=F013117 6AA46D5DB\&tid=1A8C498AF5F8AF5D. Chinese.

[15] Laszlo A, Krippner S. Systems Theories:Their Origins, Foundations, and Development. In Jordan JS,ed. Systems Theories and A Priori Aspects of Perception. Amsterdam: Elsevier Science Publishing; 1998; 3: 47-74. https ://doi.org/10.1016/S0166-4115(98)8 0017-4

[16] Johnson-Laird PN. Mental models and cognitive change. J Cogn Psychol. 2013; 25(2): 131-138. https://doi.org/10.1080/20 445911.2012 .759935

[17] International Organization for Standardization. ISO 31000: Risk Management: Principles and Guidelines. ISO. 2009.

[18] Cook RI. How complex systems fail. Cognitive Technologies Laboratory. Chicago, IL: The University of Chicago; 1998.

[19] Potter P, Wolf L, Boxerman S, et al. Understanding the cognitive work of nursing in the acute care environment. J Nurs Adm. 2005; 35(7): 327-335. PMid:16077274. https : //doi .org/10.1097/00 005110-200507000-00004

[20] Choi SPP, Cheung KIN, PANG SMC. Attributes of nursing work environment as predictors of registered nurses' job satisfaction and inten- tion to leave. J Nurs Manag. 2013; 21(3): 429-439. PMid:23409781. https://doi.org/10.1111/j.1365-2834.2012.01415.x

[21] Cook RI, Render M, Woods DD. Gaps in the continuity of care and progress on patient safety. BMJ. 2000; 320(7237): 791-794. PMid:10720370. https ://doi.org/10.1136/bmj .320.7237.7 91

[22] Ulrich BT, Buerhaus PI, Donelan K, et al. How RNs view the work environment: Results of a national survey of registered nurses. J Nurs Adm. 2005; 35(9): 389-396. PMid:16200006. https ://doi .org/ 10.1097/00005110-200509000-00008

[23] Bruce CR, Miller SM, Zimmerman JL. A qualitative study exploring moral distress in the ICU team: the importance of unit functionality and intrateam dynamics. Crit Care Med. 2015; 43(4): 823-831. PMid:25525754. https ://doi .org/10.1097/CCM. 0000000000 000822

[24] Reader TW, Flin R, Mearns K, et al. Interdisciplinary communication in the intensive care unit. BJA. 2007; 98(3): 347-352. PMid:17272386. https://doi.org/10.1093/bja/ael372

[25] Alexanian JA, Kitto S, Rak KJ, et al. Beyond the team: Understanding interprofessional work in two North American ICUs. Crit Care Med. 2015; 43(9): 1880-1886. PMid:26102250. https : //doi.org/10.1097/CCM.0000000000001136

[26] Ma C, Park SH, Shang J. Inter-and intra-disciplinary collaboration and patient safety outcomes in US acute care hospital units: A crosssectional study. Int J Nurs Stud. 2018; 85: 1-6. PMid:29783090. https://doi.org/10.1016/j.ijnurstu.2018.05.001

[27] Laschinger HKS, Wong CA, Grau AL. The influence of authentic leadership on newly graduated nurses' experiences of workplace bullying, burnout and retention outcomes: A cross-sectional study. Int J Nurs Stud. 2012; 49(10): 1266-1276. PMid:22727121. https://doi.org/10.1016/j.ijnurstu.2012.05.012

[28] Needleman J, Buerhaus P, Mattke S, et al. Nurse-staffing levels and the quality of care in hospitals. N Engl J Med. 2002; 346(22): 1715-1722. PMid:12037152. https://doi.org/10.1056/NEJM sa012247

[29] Doyle PA, Gurses AP, Pronovost PJ. Mastering Medical Devices for Safe Use: Policy, Purchasing, and Training. Am J Med Qual. 2017; 32(1): 100-102. PMid:27122622. https://doi .org/10.1177/10 62860616645857

[30] Buerhaus PI, Staiger DO, Auerbach DI. Why are shortages of hospital RNs concentrated in specialty care units? Nurs Econ. 2000; 18(3): 111.

[31] Ebright PR, Urden L, Patterson E, et al. Themes surrounding novice nurse near-miss and adverse-event situations. J Nurs Adm. 2004; 34(11): 531-538. PMid:15586075. https://doi.org/10.1097/ 00005110-200411000-00010

[32] Strachota E, Normandin P, O'brien N, et al. Reasons registered nurses leave or change employment status. J Nurs Adm. 2003; 33(2): 111117. PMid:12584464. https://doi .org/10.1097/00005110-2 00302000-00008

[33] Kunie K, Kawakami N, Shimazu A, et al. The relationship between work engagement and psychological distress of hospital nurses and the perceived communication behaviors of their nurse managers: A cross-sectional survey. Int J Nurs Stud. 2017; 71: 115-124. PMid:28391107. https://doi.org/10.1016/j.ijnurstu. 201 7.03 .011

[34] Cummings GG, MacGregor T, Davey M, et al. Leadership styles and outcome patterns for the nursing workforce and work environment: a systematic review. Int J Nurs Stud. 2010; 47(3): 363-385. PMid:19781702. https://doi.org/10.1016/j.ijnurstu. 200 9.08 .006 